\title{
EFL Corner in Algeria: Single-Sex vs Co-Educational Schools
}

\author{
Faiza Haddam Bouabdallah
}

\section{Abstract}

Nowadays, English is significantly popular among Algerian generation but not to such an extent to be used in social context. Its use is, however, limited to classroom environment except for those students who are fond of this foreign language and master it with a high level of fluency. The purpose of this paper is to highlight the status of English as second foreign language in Algeria, and how it has been injected within the educational system by taking into consideration social and cultural aspects. Education is a process and like other processes, it is exposed to several factors, some of which are aid and some others are obstructive. The type of school can be one of these factors that may affect teachers and students: Single-sex or coeducational schools. Algeria is a country that still offers different types of schools that have great impact on pedagogy and on learners' performance in the EFL context due to social and cultural impacts.

Keywords: Algerian context - EFL students - single-sex and co-educational schools

\section{Introduction}

Today English is not leading the world only through the increasing number of its speakers; however, its dominance reaches different domains including Education, Business, Politics, Science and Technology. Algeria has recently been in tune with Globalization, therefore the government tends to give more importance to the global language. Moreover, English has started to be recognized within the Algerian society especially among young generation impacted by the use of different social media. Thus, countries that want to join the ranks of developed nations have no way to do that except through attention to education and teaching system. Algerian educational system is shaped by several factors, the type of schools is among them: Single-sex or coeducational schools. These two different learning situations may affect teachers and students either positively or negatively.

Therefore, Algerian educators have to cope with different learning/teaching situation by taking into consideration the social and cultural aspects. In this regard, the main objectives in this research are threefold. The first one is describe the status of English language in Algeria. The second one is to scrutinize whether school type influences EFL teachers' performance. The last one is to highlight the ways by which educational 
psychology supports EFL teachers to enhance their quality of teaching in different situations.

Nowadays, the English language occupies such a global position that covers various world perspectives mainly communication, education, science, economy and culture that is why, English were implemented by Algerian policies within the educational system. Presently, it gains its status as a Second Foreign Language (FL2); however, the government started to give more importance and shed light on this global lingua franca to gain a new and higher status in Algeria as a First Foreign Language (FL1).

Therefore, one of the pillars of educational processes is the teaching process through which the student is provided with knowledge and experiences, but its role does not stop here only, but goes beyond that to develop the abilities, aspects of learners, and here the role of educational psychology. The teaching process in general, and the teacher in particular, are exposed to several influencing factors, as studies confirmed that there is an educational gap between the male and female category, and this is what was confirmed by educational psychologists at the American Johns Hopkins Institute.

\section{Theoratical Background}

\section{Historical Background of the Linguistic Situation in Algeria}

There have been a set of events that characterized the history of linguistic situation in Algeria. During French colonization, Algeria has witnessed a chaotic language planning that aimed to eliminate both mother tongue (Arabic) and the culture of Algerian population and replace them with the French one. However, immediately after independence the government started a set of reforms implementing different policies especially within the field of education in order to retrieve the value of Arabic as well as Arabo-islamic culture. It was such a decision in which the English language were injected into the educational system aiming to reduce the status of French in Algeria.

\section{The Status and Spread of English in Algeria}

After the Arabization reforms in 1971 and the financial changes occurring around the world, the role of English as a conveying vehicle increased more space inside globalized Algeria. Therefore, starting from 2013, the use of French begun to blur away at the cross-streets leaving more space to English among young generation. (Mami, 2013, P. 910).

It is clearly understood that the phenomenon of Globalization has a great effect on the Algerian nation. In this regard, English tends to gain more power and importance in Algeria thanks to its global status instead of French. According to Rezig (2011, P. 1330), by 1993, the government attempted to give the opportunity to young children to learn English in the primary schools in addition to French as a Second Foreign Language. The process was to give choice to pupils between French and English. 
However, the process did not cover all the primary schools since the primary statistics showed that French was the preferred language among parents. To sum up, at the beginning of the 90s, English was considered as a FL2 and as FL1 after the 2000 reform (Mami, 2013), to gain later the status of language of science and technology (Berrabah, 2014) used as a medium of instruction in some faculties in Algerian universities in recent years.

\section{Single-sex and coeducational schools}

Since the school environment, and more specifically the type of school, influences students' academic accomplishments, it may also have an impact on teachers' performance. The type of school can be determined based on the gender composition of the students, whether it is a single-sex school or a mixed school.

As for single-sex school "single-sex education refers most generally to education at to elementary, secondary, or postsecondary level in which males and females attend school exclusively with members of their own sex"(Mael at al,2005, P.1).Accordingly, single-sex school is designed for specific gender only, be it male or female. Concerning mixed schools, also known as coeducational schools, are an integrated educational system where both sexes are taught together in the same institution. (Spender \& Karamarae, 2004).

\section{Advantages and disadvantages of single-sex and coeducational schools}

From the above-mentioned definitions, it is essential to discuss the advantages and disadvantages of both types of schools. There are numerous advantages to single- sex schools, which outweigh its drawbacks. One of the benefits stated by Finn (1980), is that single-sex schools promote higher academic achievement and social solidarity based on a shared gender identity (cited in Radford,1998).In addition to that, students in single-sex schools receive more attention and guidance from their teachers. Furthermore, students' experience in single-sex classrooms improve their performance and confidence by allowing a better match for teaching and learning (McNeil, 2008).

Another advantage is that students tend to express themselves more during discussion group, as they are not intimidated by the presence of the opposite sex(Spielhagen,2006); especially girls as they "feel less inhibited and devote more time to academic work"(Spender and Karamarae,2004, P. 522). Single-sex school not only stimulates students, but also their teachers; as it gives teachers the opportunity to focus more on teaching and learning and less on conflict between students. In addition, single-sex classes become a safe environment where bullying, violence and distraction are reduced (Blair \& Sandford, 1999).Therefore; students get more involved and participate in the work proposed by their teachers. The latter will be more creative and innovative in their educational activities (Rex \& Chadwell, 2009).Single-sex education is not without its disadvantages, however. According to Guarisco (2010), single-sex schools cannot prepare students for real world situations 
(cited in Ogden, 2011).Moreover, single-sex schools exacerbate gender stereotypes and inequality. In single-sex schools, students promote poor social skills.

Apart from what has been stated, there are several advantages of coeducation schools. One advantage is that coeducational schooling provides a natural social environment. Another feature is that coeducational schools are committed to treat boys and girls equally.(Spender \& Karamarae,2004).Additionally, Sather (2005, P. 215) claims that "competition between sexes is greater than between same-sex rivals, and this competition leads to higher standards of academic achievement". Conversely, as a downside of coeducational schools, the different sexes may distract each other.

Another drawback, coeducation ignores the existence of gender differences in interests and aptitudes (Schneider \& Coutts, 1982).From Lorenzi-Cioldi's (1988) point of view, stereotypes in mixed classes are reinforced. Girls are likely to be interested about their image, and boys are likely to impress girls. Finally, coeducation may adversely affect students' academic achievements because both genders' interest may be more dependent on non-academic factors rather than on academic achievements. (Coleman, 1961).

\section{Pratical Side}

\section{Research design}

To address the research objectives, the researchers opt for the exploratory research. The current research work employed both qualitative and quantitative methods as well as a combination of primary and secondary sources. As for data collection, two research instruments were used: the "teachers' questionnaire" and the "inspectors' interview".

\section{Teachers' profile}

The investigation covered a sample of 23 teachers, males and females, working in three single-sex schools namely: Ibn Kheldoun, Elmakarri, and Salima Taleb middle schools situated in Tlemcen (West Algeria), wherein they teach English as a Foreign Language (EFL). These teachers have had teachers experience in both types of school i.e. single-sex and coeducational schools. Those teachers obtained their degrees from diverse institutions: sixteen of the participants graduated from university and seven of them have received a training course from ITE (Institut Technique de L'enseignement).

\section{Inspectors' profile}

The interview was conducted with three inspectors males and female in the secondary school « Motkan Ibn Saad » situated in Tlemcen which is also teacher training center, and all of them were teachers for more than ten years in both types of school i.e. single-sex and coeducational schools. All the inspectors obtained their degrees from university of Tlemcen "Abou Bekr Belkaid University". They also 
received a training course from Education Inspectors Training Center in Algiers for one year.

\section{Discussion of the main results}

This section will spotlight on discussing the main results that emerged from the teachers' questionnaire and inspectors' interview. The analyzed data do not reveal any significant differences between single-sex and coeducational schools with regard to the teaching process. Indeed, teachers' answers show that teaching is the same in both types of schools as the same teaching methods are used in the two settings. What differs is the way in which teachers treat their students according to level of knowledge acquisition whereby they respect the individual equity between students. The inspectors who emphasized that teaching in single-sex portrayed the same picture and co-educational schools is identical owing to the fact that teachers undergo the same training and use the same teaching methods. Furthermore, teachers report that there are no specific teaching strategies for each type of school because the current educational system stipulates that the focus is on the learner, but they noticed a better challenging environment in mixed schools rather than in single-sex schools. Regarding the teachers' performance in both types of schools, though more than a half of the total number reveal that their performance varies since the type of school affects them, $47.8 \%$ of teachers opposed this fact arguing that their performance remains the same in both settings without any effect. In the same realm of thought, the inspectors believed that the school type does not affect teachers' performance for a simple reason that the work plan is the same.

Regarding the ways educational psychology refine teachers' performance in both types of schools, interesting results were obtained. Teachers reveal that educational psychology plays a pivotal role in promoting the teaching and learning process as it provides concepts, principles and methods that help in recognizing students' psychological and social differences. In addition, teaching cannot be conducted without taking into account the psychological aspect. The inspectors who asserted that knowing the students' mental abilities helps the teachers managing effectively the classroom that pictured a similar view. Teachers also confess that educational psychology is an essential part in teacher training. All these results come down to the same concluding point, holding that educational psychology provides teachers with strategies and methods that help them identifying students' individuals and mental abilities for an effective and productive teaching-learning process and for a positive learning environments for better learners' achievements.

\section{Conclusion}

The collected data indicate that teachers and inspectors were aware of the important role-plays by educational psychology. Educational psychology allows teachers to know how to think, how the learning process should be underway, how to inspire and how to memorize or remember. It allows teachers to guide students and canalize their 
skills in the right direction. On the other hand, teachers and inspectors have stated that there are no differences between single-sex or co-educational schools neither in the teaching process nor in the performance of teachers but rather a different challenging environments.

In addition, this research work sheds light on the spread of English language in Algeria and its status within the educational system. It is obvious that English is globally spread because of its international position, but it is still thought at different levels as a second foreign language in Algeria expect for the tertiary level where English is used as a medium of instruction for technical and scientific fields. Based on that claim, there is an urgent necessity to reformulate the actual language policy and planning in Algeria to give English it right position among the Algerian new society.

In the light of all, the educational authorities ought to enact decisions to construct institutions for teacher training as these settings help teachers in their educational journey; by providing courses such as educational psychology. This latter is a substantial aspect in the teaching-learning process as it increases teachers' awareness about students' psychological and social differences.

\section{References}

[1] Benrabah, M. (2014). Competition between Four "World" Language in Algeria. Journal of Language. Journal of World Languages, 1(1), 38-59.

[2] Blair, H. \& Sanford, K. (1999). Single-sex Classrooms: A Place for Transformation of Policy and Practice. Annual Meeting of the American Educational Research Association, Montreal, Quebec, Canada.

[3] Coleman, J. S. (1961).The Adolescent Society. New York: Free Press.

[4] Dickey, M.W. (2014). Gender-Specific Instructional Strategies and Student Achievement in $5^{\text {th }}$ Grade Classrooms.(Doctoral dissertation, University of South Carolina).Retrieved from https://scholarcommons.sc.edu/etd/2624

[5] Karamarae, C. \& Spender, D. (2004). Routledge International Encyclopedia of Women: Global Women's Issues and Knowledge. New York and London: Routledge.

[6] Lorenzi-Cioldi, F. (1988) .Individus dominants et groupes dominés: images masculines et féminines: Presses Universitaire de Grenoble.

[7] Mami, A. (2013). Teaching English under the LMD Reform: The Algerian Experience. International Journal of Social, Behavioral, Educational, Economic, Business and Industrial Engineering, 7 (4), 910-913

[8] Ogden, C.E. (2011). A Comparison of Students Performance in Single-sex Education and Coeducational Settings in Urban Middle Schools. (Doctoral dissertation, Georgia Southern University, Georgia). Retrieved from

https://digitalcommons.georgiasouthern.edu/cgi/viewcontent.cgi?article=1 361\&con text=etd 
[9] Rex, J. \& Chadwell, D. (2009). Single-gender Classrooms. School Administrator,

[10] 66 (8), 28-33.

[11] Sather, T. (2005). Prons and Cons: A Debater's Handbook. London and New York: Taylor \& Francis e-Library.

[12] Schneider, F.W. \& Coutts, L.M. (1982). The High School Environment: A Comparison of Coeducational and Single-sex Schools. Journal of Educational Psychology.vol 74. No 6, 898-906. 